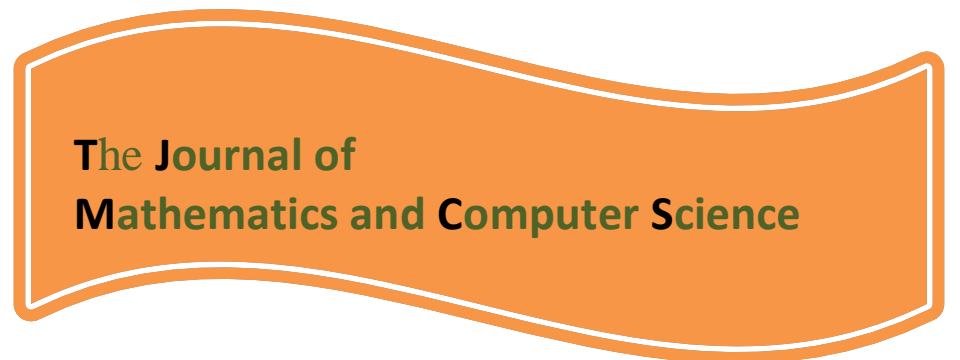

Available online at

http://www.TIMCS.com

The Journal of Mathematics and Computer Science Vol.2 No.1 (2011) 195-207

\title{
An Appraisal and Ranking of the effective factors on Performance of Branches of Melli Bank of Iran In Mazandaran Province by Using of AHP-FUZZY Technique
}

\author{
A. Sorayaei1 ${ }^{*}$, S. A. Sajjadi Amiri and S. M. Sajjadi Amiri \\ Islamic Azad University, Babol Branch, Babol, Mazandaran, Iran \\ a.sorayaei@gmail.com
}

Received: August 2010, Revised: November 2010

Online Publication: January 2011

\begin{abstract}
The purpose of this research is appraisal and ranking of effective factors on performance of branches of melli bank of Iran in mazandaran province by using of AHP technique. as for literature review of organizational performance, needed data was collected by use of instruments with documents, interviews and questionnaire, with non experimental research methodology, by considerations experts' viewpoint in group AHP technique for priority.

the results of this research to imply between 4 criteria, asset, management, personnel, customers and and between 27 selector switch, rate of asset absorption, profitability, decrease the delayed demanding, expertise, trust \& respect to the personnel, have highest priority relation to other alternatives.
\end{abstract}

Keywords: appraisal, ranking, performance, branches of Melli Bank of Iran, FUZZY-Analytical Hierarchy Process (AHP-FUZZY).

\section{1-Perface}

The appraisal of performance is a extensive subject on which a wide range of fields \& authorities had affected. The history of appraisal of performance in its primary shape goes back to longtime ago, the time when man began a social life and applied the phenomenon of duty division among the members. At this time, the appraisal of performance existed in its primary form, in a way that the members succeeded to gain award \& probably promotion of position. This kind of appraisal was formed based on metal \& personal judgment of the authorities \& was posed in a general form such as good \& bad. With the passing of the time, complexity of duties \& growth of expectations \& demands, appraisal of perform once coordinated itself with these changes. Appraisal system, in both individual \& organizational level, was

\footnotetext{
$1, *$ - Corresponding author: Assistant Professor
} 
introduced in loom industry by Robert Owen in 1800 AD in Scotland. The usage of wood in different colors in order to accept or reject the produced materials, was in fact an appraisal of the quality of the organization, white as excellent performance, yellow as good performance, blue as average performance, \& black as the worst performance of the individual \& organization. The process of appraisal of performance has progressed in comparison with the past. For example we can mention the appraisal of personnel, appraisal of management \& the change \& progress of appraisal indexes in the form of presenting general principles for appraising organizations \& comprehensive management quality, therefore the scope of usage of appraisal of performance has expanded to all dimensions \& aspects of human \& organizational activities \& in fact the subjects which are posed in the newest scientific fields are directly or indirectly, related to the appraisal of performance( saghe'ei, 1387).

Appraisal of performance of government \& governmental organizations is also very significant. The official form of this attitude which is based on scientific achievements begins with the investigation system. Sweden is the first country where the indagation system was realized. Appraisal of performance was posed seriously after the end of World War II \& the dominance of kinsy's attitudes at that time. Because of war condition \& growth of interference of the government in the countries after the end of war, the amount of effectiveness \& necessity of government interference was questioned by economic theorizer \& this creates the basis of appraisal of government role in economy and the literature of appraisal of government performance was posed more carefully. The most important case of the appraisal of government policies in the developing countries relates to the ending of the first decade of their independence in which the results of the tendency of these countries during cold war to each of the two poles in the east \& west( America \& U.S.S.R) \& assumption of the presented policies by them were appraised \& the ambit the method of the government interference in these countries were verified(I bid, p3, shirchi, 1388).

The appraisals around the economic adjustments \& also the appraisals of communist governments are examples of such appraisals. Today also the appraisal performance of government \& governmental organizations applicative with the complication of government interference in each country is one of the most important step of the planning of these countries in a way that this process is being applied in both developing \& developed countries(I bid, p4).

Appraisal is an activity whose nature is didactic, economic, social \& cultural. So there should be made a comparison between implicit \& mentioned goals $\&$ expected $\&$ unexpected results $\&$ then we should appraise the effect of this result on economic, social \& cultural environment. Appraisal is a process which practices the appraisal \& measuring, valorizing \& judging a performance during a special period (yazdchi, 1383).

The process of catholic appraisal of performance is predicated in the form of phrases such as efficiency, effectiveness, meaningfulness, enabling, response capability in the frame of principles \& concepts for the realization of organization goals \& duties, structural, programmatic goals, and longterm development of the organization. This process is called organization appraisal of performance ( saghe'ei, 1387).

Townley believes that the appraisal of performance as one of human source technique consists of "hierarchical categorization of people". In other words, the aim of appraisal of performance is granting privilege to people based on favorite performance objective criteria and standards. Therefore the following factors are effective on appraisal of performance: 1- personal factors - skills - abilities motivations \& commitment. 2- Leadership factors - advocation \& support, guidance \& encouragement of manager \& supervisor. 3- System factors - information technology, administrative \& communicational 
A. Sorayaei, S. A. Sajjadi Amiri and S. M. Sajjadi Amiri/ TJMCS Vol .2 No.1 (2011) 195-207

systems. 4- Situational factors - pressures \& alteration inside organization \& its outside consisting market, economic development \& occupational position (yazdchi, 1383).

Appraisal of performance is a tool which firms use to be ensured of execution of strategies. Usually strategies undergo some changes through the time. Therefore, appraisal criteria should change according to them, but these criteria often stay the same. The reason of unsuccessfulness of firms is that there is no logical relation between strategies \& their selected appraisal criteria.(Hossein-Abbasi \& Mostaan, 1388)

Appraisal performance of organizations is an effective tool for indagating \& determining the level of goal \& results achievement. Determining the importance coefficient of each criteria is also very important since it determine the emphasis of the appraisers from the aspect of kind of activity \& the level of importance for directing the behavior of the subject of appraisal. Therefore, using decision making models such as Analytic Hierarchy Process (AHP) and other models for the aim of ranking approbated criteria is inevitable.( Azar \& et al., 1384)

Ali (2003) indagated the necessity of creating \& using an appraisal of performance system in small \& average firms in a study titled frame work of appraisal of performance for small \& average firms which was done in a firm at Edmonton in Canada. In this study the appraisal of performance system consists of two parts \& the final results showed that the factors which are effective on the results of analysis, helps us to define the effects of these factors on the results. Therefore, the active frameworks of appraisal of performance can support the organization in order to codify the strategies \& it's effective on the internal processes of organizations based union \& accretion of external factors. Imad Alsyouf (2006), based on his studies, presented on strategic system for measuring the performance of preservation. He applied the framework of balance privilege cart in order to appraise the contribution of the part of preservation \& protection for the aim of achieving strategic goals. He found out that by the use of adjusted balanced privilege cart. It'll be possible to identify the top relation of a strategy which is effective on preservation \& protection \& appraise its effect on institute competitive patents. Alsyouf's subjective study which was done in a paper factory in Sweden, confirmed his findings based on the fact that preservation \& protection is no more a sumptuary center. Azar \& et.al(1384) contoured a mathematical model of appraisal of performance of industry \& mine ministry based on the model TOPSIS, AHP \& SAW. By regarding appraisal of performance criteria, this ministry based on the determiner's opinions \& compilation of the results of three methods of processes Appraisal Hierarchy Process(AHP), Simple Assortment Weighting(SAW) \& the method of the closest answer to the ideal(TOPSIS), achieved the optimum mixture of criteria for performance measurement of this ministry. Meanwhile, defining the level of efficiency of the above mentioned methods based on dispersion coefficient signifies the predominancy of TOPSIS.

The goal of this study is identifying the effective factors on organization performance \& defining the importance degree (ranking) of these factors on organization performance with the attitude of AHPFUZZY in order to recognize the improvement barriers \& deterrent factors \& run basic \& newer activities for the intent of improvisation according to value \& authenticity of them.

Therefore the present study is managerial \& is concerned with the subject of performance. It studies identifies the effective factors of the performance of Mazandaran Melli Bank branches. The local domain \& studies zone in this study is limited to Melli Bank branches at the whole Mazandaran Province. Therefore the question of the study is posed like following 1: what are the criteria of appraisal of performance of Mazandaran Melli Bank branches? \& 2: How is the performance ranking of these branches based on the determined criteria? 
The subjective domain of the present study consists of the aesthetics related to appraisal of performance \& its locative zone is Mazandaran Melli Bank branches. The study variants based on their constitution in answering to the questions or testing the hypothesis is divided to four criteria including customer, management, personnel, and asset.

Element relating to the criteria of customer include : branch location, average waiting time, credit granting criteria, behaving manner towards customer, modern service presentation, recognition \& attention to customer demand, financial consultation to customers.

Elements relating to asset criteria: decrease the delayed demanding, profitability, rate of asset absorption, decrease the extra expenditure.

Elements related to management criteria: the method of appraisal performance, method of control \& supervision, representing goals \& organization plans, budgeting \& resource allotment, management informational system, continual innovation, welfare for personnel \& his family, reward system(encouragement \& punishment), salary system, trust to personnel.

Elements relating to personnel criteria: expertise \& knowledge, instruction, experience, work conscience, organizational commitment, innovation.

\section{2- Instrumentation and methods}

There are different methods for defining the validity of measuring tools. One of them is questioning from experts ( Sorayaei \& Pakdin, 2008). The questions of the measuring tools of current study in valid since the components of variants that are being measured are taken from the research subjective literature \& in other words all experts are in agreement with them. Moreover, the designed questionnaire was given to the experts \& masters as a pretest \& after executing their corrective opinions, the final questionnaire was prepared \& used for data gathering.

As it was mentioned, the present study is a descriptive \& mensurable kind of study, in a way that in the beginning the Delphi opinion unit defines the effective factors on organization performance by gathering the ideas of experts by questionnaire \& them define the order of impressments of factors by applying AHP-FUZZY method. The statistic society of the present study consists of the twelve experts of Mazandaran Melli Bank, accidentally from the city Babol. The number of chosen people regarding the number of branches in Babol, is one person from each branch. In Delphi method for making decision about a special case, a sophisticated group is selected $\&$ their opinions are gathered via a questionnaire. After that, their opinions are classified \& are sent to the members. They recheck the opinions \& give score according to their own opinions. The researcher gathers \& indagate them \& chose the most scored one as the most suitable decision. In this method the members don't know each other \& the group pressure is reduced to a minimum amount (alvani, 1379).

After gathering required data \& codifying them, they were put in Excel program to be categorized, processed \& appraised. In this study, which is descriptive, data gathering was done by free method \& questionnaire.

The method of hierarchical analysis I one of the most comprehensive designed system for decision making by using multiple criteria, because this technique provides the probability of formulating the affair hierarchically \& also is capable of regarding the various quantitative and qualitative criteria in the affair. This process applies various choices in decision making and is capable of analyzing the sensitivity on the criteria \& sub criteria. In addition, the base of duad comparison which facilitates the judgment and calculation is the excellent benefits of this technic in multiple criteria decision making (Asgharpour, 1383). 
The Fuzzy prescription of the AHP technique encompasses the vague or not truly described situations. Different method of AHP-FUZZY, are the systematic approaches for selecting the choice by using the conception, the theory of FUZZY complexes and analysis of the hierarchical structure. In the year 1996 a method names Extent Analysis method (EA) was offered by a Chinese researcher named Chang .The numbers used in this method are triangular numbers (Momeni, 1384) .

The most important affair in priority processing is the determine the choices correctly. In order to have a correct selection, determining criteria are needed. For achieving this goal, a large amount of researchers \& articles were studied. The result of these studies was the derivation of 4 criteria of priority processing \& 27 choices of effective factors for performance appraisal. In the next step these 27 choices were indexed in a questionnaire to be distributed among experts. Then their arithmetic average was calculated for combination of charters. These choices (from A1 to A27) were indexes in the table No.1.

Table No, 1- tested choices of AHP-FUZZY

\begin{tabular}{|c|c|c|}
\hline Title & criteria & choices \\
\hline$A_{1}$ & \multirow{7}{*}{ personnel } & branch location \\
\hline$A 2$ & & average waiting time \\
\hline$A 3$ & & credit granting criteria \\
\hline$A_{4}$ & & $\begin{array}{l}\text { behaving manner towards } \\
\text { customer }\end{array}$ \\
\hline$A 5$ & & modern service presentation \\
\hline$A_{6}$ & & $\begin{array}{l}\text { recognition \& attention to } \\
\text { customer demand }\end{array}$ \\
\hline$A_{7}$ & & $\begin{array}{l}\text { financial consultation to } \\
\text { customers }\end{array}$ \\
\hline$A_{8}$ & \multirow{4}{*}{ asset } & $\begin{array}{c}\text { decrease the delayed } \\
\text { demanding }\end{array}$ \\
\hline$A_{9}$ & & profitability \\
\hline$A_{10}$ & & rate of asset absorption \\
\hline$A_{11}$ & & decrease the extra expenditure. \\
\hline$A_{12}$ & \multirow{7}{*}{ management } & $\begin{array}{c}\text { the method of appraisal } \\
\text { performance }\end{array}$ \\
\hline$A_{13}$ & & method of control \& supervision \\
\hline$A_{14}$ & & $\begin{array}{c}\text { representing goals \& } \\
\text { organization plans }\end{array}$ \\
\hline$A_{15}$ & & budgeting \& resource allotment \\
\hline$A_{16}$ & & $\begin{array}{l}\text { management informational } \\
\text { system }\end{array}$ \\
\hline$A_{17}$ & & continual innovation \\
\hline$A_{18}$ & & $\begin{array}{l}\text { welfare for personnel \& his } \\
\text { family }\end{array}$ \\
\hline
\end{tabular}




\begin{tabular}{|c|c|c|}
\hline$A_{19}$ & \multirow{5}{*}{} & reward system \\
\hline$A_{20}$ & & salary system \\
\hline$A_{21}$ & \multirow{5}{*}{ personnel } & trust to personnel \\
\hline$A_{22}$ & & expertise \& knowledge \\
\hline$A_{23}$ & & instruction \\
\hline$A_{24}$ & & experience \\
\hline$A_{25}$ & & organizational commitment \\
\hline$A_{26}$ & & innovation \\
\hline$A_{27}$ & & \\
& & \\
& & \\
\hline
\end{tabular}

For assessment of the performance appraisal factors, assessment index must be defined and ranked. Since in this indagation, assessment is done buy using multiple and qualitative indexes and step by step, AHP (the process of hierarchical analysis) is a good method for this aim. Since most of the managers express their preferences \& ideas in lingual idioms instead of a numerical amounts, in priority processing of performance appraisal factors a AHP FUZZY frame was applied.

The selected method is for using AHP FUZZY technique, the method of extension analysis (EA) for valuating the indexes \&choices (Chang, 2001).

To overcome the uncertainly of affairs input parameters, decision making was done gregariously, that the ideas of experts \& the collection of their opinions was spotted as the final decision in each s special case (Kahraman , 2003).

A) Formation of hierarchial model: In this study, according to this method, first hierarchy of decision for ranking of performance appraisal factors is designed. To form the hierarchial model, we should first determine its three main level. The first level which is the highest level of hierarchial model is the aim of decision making that is ranking of the importance of performance appraisal factors of. the second level of hierarchial model after the aim, is criteria or criteria underlying the aim. In the present study, the criteria are customer, financial, management \& personnel ones. The third level of hierarchial model, are choices. Choices are infact, the destination of the hierarchial model. (From A1 to A27). The graph No. 1 shows the structure of hierarchial model.

B)

C) Designation of Matrix duad comparison: The aim of this step is to determine the values of criteria \& ranking of factors. Therefore business using the study hierarchial model (graph No, .1) the tables of duad comparisons are formed. In the first step the ideas \& preferences of experts about the importance of criteria \& choices are collected in the form of natural language words in the format of duad comparisons matrix \& then according to the conventional table of conversion in the EA method are converted to FUZZY numbers, then the FUZZY average of ideas is calculated \& finally the average of preferences in the form of triangular FUZZY numbers in the format of duad comparisons matrix is regulated. 


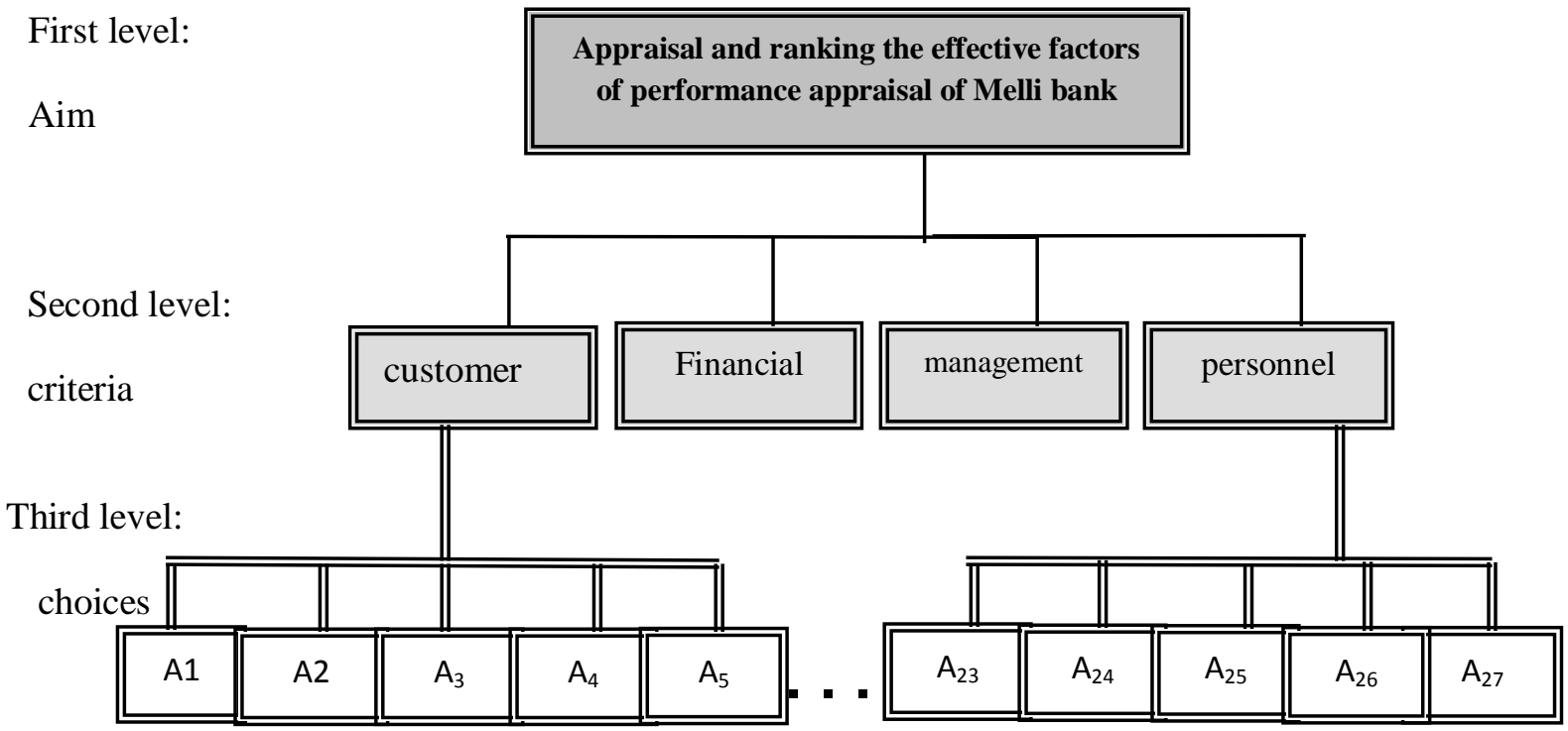

Tabulate No.1-hierarchy of decision for ranking the performance appraisal factors of

First step: conversion of mental ideas of the experts to quantitative amounts: In this step the ideas of experts about the importance of choice to each other regarding to each criteria should be achieved .In such studied most of experts ideas are expressed in the format of natural language words and infact the grasp of experts ideas are mental. While these words can be regarded as lingual amounts and be described by FUZZY logic. Since in the method of Expansion Analysis, triangular Fuzzy numbers are used to show the amount of preferences, according to the below conventional table lingual variants (expert's preferences) are converted to triangular Fuzzy numbers:

Table No. 2- Conversion of lingual variants to triangular Fuzzy numbers

\begin{tabular}{|c|c|c|}
\hline \hline Lingual variant & Triangular Fuzzy number & The reverse of triangular fuzzy number \\
\hline \hline excellent & $(1,1,1)$ & $(1,1,1)$ \\
\hline The best & $\left(\frac{1}{2}, 1, \frac{3}{2}\right)$ & $\left(\frac{2}{3}, 1,2\right)$ \\
\hline better & $\left(1, \frac{3}{2}, 2\right)$ & $\left(\frac{1}{3}, 1\right)$ \\
\hline average & $\left(\frac{3}{2}, 2, \frac{5}{2}\right)$ & $\left(\frac{2}{2}, \frac{2}{3}\right)$ \\
\hline little & $\left(2, \frac{5}{2}, 3\right)$ & $\left(\frac{2}{3}, \frac{1}{2}\right)$ \\
\hline very little & $\left(\frac{5}{2}, 3, \frac{7}{2}\right)$ & $\left(\frac{2}{7}, \frac{1}{3}, \frac{2}{5}\right)$ \\
\hline
\end{tabular}

Second step: consensus of expert's opinions: In order to determine the preferences in duad comparisons matrix, the consensus of a group of experts' opinions in the field of performance appraisal was used. Since the analysis of complex affairs needs the opinions of several experts, in decision making 
by using the opinions of several experts their opinions are combined or adapted to achieve a unit decision.

Making decision by using the opinions of several experts is called afflux(consensus).Since the experts opinions are expressed in the form of natural language words and can be regarded as lingual amounts \& be described by Fuzzy logic, therefore the consensus of their opinions can be achieved through Fuzzy average.(Momeni ,1384).

As for making Fuzzy the importance of performance appraisal, triangular Fuzzy numbers were used, the consensus of experts opinions in this field, is calculated according to the below triangular average formula (the importance of opinions is assumed to be equal).

Assume $\mathrm{n}$ triangular numbers:

$$
\mathrm{A}_{\mathrm{i}}=\left(\mathrm{a}_{1}{ }^{(\mathrm{i})}, \mathrm{a}_{\mathrm{M}}{ }^{(\mathrm{i})}, \mathrm{a}_{\mathrm{r}}{ }^{(\mathrm{i})}\right) \quad i=1, \ldots, n
$$

Usage of the pluralization of triangular numbers \& dividing it on a real number concludes to triangular average Aave, the result is a triangular number that was shown in formula 1.

$$
\begin{aligned}
& A_{\text {ave }}=\frac{A_{1}+\ldots+A_{n}}{n}=\frac{\left(\sum_{i=1}^{n} a_{1}^{(i)}, \sum_{i=1}^{n} a_{M}^{(i)}, \sum_{i=1}^{n} a_{2}^{(i)}\right)}{n} \\
& A_{\text {ave }}=\left(m_{1}, m_{M}, m_{2}\right)=\left(\frac{1}{n} \sum_{i=1}^{n} a_{1}^{(i)}, \frac{1}{n} \sum_{i=1}^{n} a_{M}^{(i)}, \frac{1}{n} \sum_{i=1}^{n} a_{2}^{(i)}\right)
\end{aligned}
$$

Third step: The formation of duad comparison Matrix: In the next step with the help of acquired Fuzzy averages, duad comparisons matrix of criteria to each other and that of choices to each criteria is formed. In each of this matrix, each of the blocks upon the main diagonal shows the degree of importance of the row elements to column elements and each of the blocks under the main diagonal shows the degree of importance of the column elements to row elements and their value is reverse of the value of the blocks upon the diagonal. For instance the matrix of criteria (customer, asset, management \& personnel) C1 TO C4 was shown in the table 3.

Table No. 3-Example of the present study duad comparison matrix creteria

\begin{tabular}{|c|c|c|c|c|}
\hline creteria & $C 1$ & $C 2$ & $C 3$ & $C 4$ \\
\hline \hline$C 1$ & $(1,1,1)$ & $(2 / 5,1 / 2,2 / 3)$ & $(5 / 2,3,7 / 2)$ & $(2 / 7,1 / 3,2 / 5)$ \\
\hline$C 2$ & $(3 / 2,2,5 / 2)$ & $(1,1,1)$ & $(3 / 2,2,5 / 2)$ & $(2,5 / 2,3)$ \\
\hline$C 3$ & $(2 / 7,1 / 3,2 / 5)$ & $(2 / 5,1 / 2,2 / 3)$ & $(1,1,1)$ & $(2 / 7,1 / 3,2 / 5)$ \\
\hline$C 4$ & $(5 / 2,3,7 / 2)$ & $(1 / 3,2 / 5,1 / 2)$ & $(5 / 2,3,7 / 2)$ & $(1,1,1)$ \\
\hline
\end{tabular}

The data of the table No.3 was achieved by regarding to the average of the owners responded in the Likert spectrum of questionnaire and their Fuzzy average was defined, was converted to triangular Fuzzy numbers business using table No.2.

C) Calculation of the coefficients of duad comparisons matrices: After the formation of duad comparisons metrics and gathering data, it's turn to calculate the values of elements .For calculating the 
values, first the coefficients of each duad comparisons matrices and the amount of largeness of the elements to each other should be calculated, According to EA method, the coefficients of the matrixes are calculated based on the below formula. (Asgharpour, 1383)

$\mathrm{S}_{\mathrm{K}}=\sum_{\mathrm{j}=1}^{\mathrm{n}} \mathrm{M}_{\mathrm{KL}} \times\left[\sum_{\mathrm{j}=1}^{\mathrm{m}} \sum_{\mathrm{j}=1}^{\mathrm{n}} \mathrm{M}_{\mathrm{ij}}\right]^{-1}$

K shows the number of row \& i \& j are respectively choices \& criteria.

For example for the table of present study substructions the amount of duad comparisons matrix coefficients shown in the table No.3 are calculable according to following processes:

Table No. 4- Example of calculation of matrix coefficients for the present study matrix criteria

(based on the formula)

\begin{tabular}{|c|c|c|c|c|c|}
\hline substructions & $\sum_{J=1}^{N} \mathrm{M}_{\mathrm{KL}}$ & \multirow{5}{*}{$x$} & $\sum_{J=1}^{M} \sum_{J=1}^{N} M_{I J}$ & \multirow{5}{*}{$=$} & $\mathrm{S}_{\mathrm{K}}$ \\
\hline Customer & $(4.18,4.83,5.56)$ & & $(0.0391,0.046,0.054)$ & & $(0.163,0.222,0.300)$ \\
\hline Asset & $(6,7.5,9)$ & & $(0.0391,0.046,0.054)$ & & $(0.235,0.345,0.486)$ \\
\hline Management & $(1.68,2.67,2.46)$ & & $(0.0391,0.046,0.054)$ & & $(0.066,0.123,0.133)$ \\
\hline Personnel & $(6.33,7.4,8.5)$ & & $0.0391,0.046,0.054)($ & & $0.247,0.340,0.459)($ \\
\hline
\end{tabular}

After calculation of $S_{K}$, we should calculate the degree of their largeness to each other. Generally if M1 \& M2 are two triangular Fuzzy numbers, the degree of largeness of M1 to $M 2 V\left(M_{1} \geq M_{2}\right)$, is described as below:

$$
\begin{array}{ll}
\mathrm{V}\left(\mathrm{M}_{1} \geq \mathrm{M}_{2}\right)=1 \quad \mathrm{~m}_{1} \geq \mathrm{m}_{2} & \\
\mathrm{~V}\left(\mathrm{M}_{1} \geq \mathrm{M}_{2}\right)=\operatorname{hgt}\left(\mathrm{M}_{1} \cap \mathrm{M}_{2}\right) & \text { Unless } \\
\operatorname{hgt}\left(\mathrm{M}_{1} \cap \mathrm{M}_{2}\right)=\frac{\mathrm{u}_{1}-\mathrm{l}_{2}}{\left(\mathrm{u}_{1}-\mathrm{l}_{2}\right)+\left(\mathrm{m}_{2}-\mathrm{m}_{1}\right)} &
\end{array}
$$

The amount of largeness of a triangular Fuzzy number from the $\mathrm{k}$ of another triangular Fuzzy number is also calculated from the following formula:

$$
\mathrm{V}\left(\mathrm{M}_{1} \geq \mathrm{M}_{2}, \ldots, \mathrm{M}_{\mathrm{K}}\right)=\mathrm{V}\left(\mathrm{M}_{1} \geq \mathrm{M}_{2}\right), \ldots, \mathrm{V}\left(\mathrm{M}_{1} \geq \mathrm{M}_{\mathrm{K}}\right)
$$

For example for the table of present study subtraction, the amount of largeness of triangular Fuzzy number of customer Criteria to each of asset, management \& personnel Criteria are calculable as the table No.5 shows:

Table No.5- the example of calculation of the amount of largeness of triangular Fuzzy number of customer Criteria to other Criteria (based on the formula 3)

\begin{tabular}{|l|l|l|l|l|l|}
\hline largeness & $=$ & & $=$ & \\
\hline
\end{tabular}


A. Sorayaei, S. A. Sajjadi Amiri and S. M. Sajjadi Amiri/ TJMCS Vol .2 No.1 (2011) 195-207

\begin{tabular}{|c|c|c|c|}
\hline $\begin{array}{l}\text { customer criteria to asset } \\
\text { ones }\end{array}$ & $\mathrm{V}\left(\mathrm{S}_{1} \geq \mathrm{S}_{2}\right)$ & $\frac{(0.300-0.235)}{(0.300-0.235)+(0.345-0.222)}$ & 0.345 \\
\hline $\begin{array}{l}\text { customer criteria to } \\
\text { management ones }\end{array}$ & $\mathrm{V}\left(\mathrm{S}_{1} \geq \mathrm{S}_{3}\right)$ & $\frac{(0.300-0.066)}{(0.300-0.066)+(0.123-0.222)}$ & 1 \\
\hline $\begin{array}{l}\text { customer criteria to } \\
\text { personnel ones }\end{array}$ & $\mathrm{V}\left(\mathrm{S}_{1} \geq \mathrm{S}_{4}\right)$ & $\frac{(0.300-0.247)}{(0.300-0.247)+(0.340-0.222)}$ & 0.187 \\
\hline
\end{tabular}

Calculation of the above table is done exactly for each of the criteria to others and finally the least amount of largeness of each criteria to others was achieved in the form of table No.6 data.

Table No.6- example of calculation of the least amount of largeness (based on the formulas 4 \& 5)

\begin{tabular}{|c|c|c|c|}
\hline customer criteria to asset ones & $\operatorname{Min} V\left(S_{1} \geq S_{2}, S_{3}, S_{4}\right)$ & \multirow{4}{*}{$=$} & 0.310 \\
\hline asset criteria to asset ones & $\operatorname{Min} V\left(S_{2} \geq S_{1}, S_{3}, S_{4}\right)$ & & 1 \\
\hline management criteria to asset ones & $\operatorname{Min} V\left(S_{3} \geq S_{1}, S_{2}, S_{4}\right)$ & & 1 \\
\hline personnel criteria to asset ones & $\operatorname{Min} V\left(S_{4} \geq S_{1}, S_{2}, S_{3}\right)$ & & 0.978 \\
\hline
\end{tabular}

D) Calculation of criteria \& choices values: After calculation of degree of largeness, for calculating the value of elements, we do as the following in duad comparison matrix:

$$
\mathrm{W}^{\prime}\left(\mathrm{x}_{\mathrm{i}}\right)=\operatorname{Min}\left\{\mathrm{V}\left(\mathrm{S}_{\mathrm{i}} \geq \mathrm{S}_{\mathrm{k}}\right)\right\}, \quad \mathrm{K}=1,2, \ldots, \mathrm{n} \quad \mathrm{K} \neq \mathrm{i}
$$

For example, the vector of $\mathrm{W}^{\prime}\left(\mathrm{x}_{\mathrm{i}}\right)$ for our study criteria matrix will be:

$$
\mathrm{W}^{\prime}\left(\mathrm{x}_{\mathrm{i}}\right)=[0.310,1,1,0.978]
$$

The choices of the above expressions are extracted from table No.6 which calculated the least amount of largeness.

Therefore, the vector of elements will be:

$$
\mathrm{W}^{\prime}=\left[\mathrm{W}^{\prime}\left(\mathrm{c}_{1}\right), \mathrm{W}^{\prime}\left(\mathrm{c}_{2}\right), \ldots, \mathrm{W}^{\prime}\left(\mathrm{c}_{\mathrm{n}}\right)\right]^{\mathrm{T}}
$$

Then the vector of abnormal coefficients of AHP-FUZZY is converted to normal values according the following expression:

$$
w_{i}=\frac{w^{\prime} i}{\sum w^{\prime} i}
$$

Finally the sum of them is calculated ( $\sum=3.688$ ) \& from dividing each of the choices on the sum of them the amount of $\mathrm{W}_{\mathrm{i}}$ will be acquired as the following:

$$
w_{i}=[0.943,0.304,0.304,0.297]^{\mathrm{T}}
$$

The achieved numbers are the number of effective factors in performance appraisal ranking in table No.7.

E) ranking of the importance of criteria \& choices: At the end, the results of calculation of the values of four criteria customer, asset, management \& personnel (from c1 to c4) \& the result of calculation of 
27 choices value related effective factors in performance appraisal (from A1 to A27) are merged vie numeral average in order to achieve the comparative import.

Once coefficients of the choices. Table $7 \& 8$ shows the results of the above calculations in sequence of the importance of the factors (choices):

Table No.7-Ranking of criteria of performance appraisal

\begin{tabular}{|c|c|c|c|}
\hline row & criteria & charter & priority \\
\hline \hline 1 & customer & 0.0943 & 3 \\
\hline 2 & asset & 0.304 & 1 \\
\hline 3 & management & 0.304 & 1 \\
\hline 4 & personnel & 0.297 & 2 \\
\hline
\end{tabular}

The calculation of table 8 will be as such that for example for customer criteria, each number of financial criteria choices of primary value column is multiplied by the value of customer criteria from table No.7 that is the amount of $0.0943 \&$ the result is the column of the primary value of the choices .This calculation was administered for the columns of final rank of customer criteria choices (and so for other criteria).

Table No.8-Ranking of effective factors on performance appraisal

\begin{tabular}{|c|c|c|c|c|c|c|c|c|c|c|}
\hline $\begin{array}{l}\text { Primary } \\
\text { value of } \\
\text { customer } \\
\text { criteria } \\
\text { choice }\end{array}$ & $\begin{array}{l}\text { Primary } \\
\text { value of } \\
\text { asset } \\
\text { criteria } \\
\text { choice }\end{array}$ & $\begin{array}{c}\text { Primary } \\
\text { value of } \\
\text { managem } \\
\text { ent } \\
\text { criteria } \\
\text { choice }\end{array}$ & $\begin{array}{c}\text { Primary } \\
\text { value of } \\
\text { personne } \\
\text { l } \\
\text { criteria } \\
\text { choice }\end{array}$ & & $\begin{array}{l}\text { The } \\
\text { value } \\
\text { of } \\
\text { criteri } \\
\text { a }\end{array}$ & & $\begin{array}{l}\text { Final rank } \\
\text { Of customer } \\
\text { criteria } \\
\text { choice }\end{array}$ & $\begin{array}{c}\text { Final rank } \\
\text { Of asset } \\
\text { criteria } \\
\text { choice }\end{array}$ & $\begin{array}{l}\text { Final rank } \\
\text { Of } \\
\text { managem } \\
\text { ent } \\
\text { criteria } \\
\text { choice }\end{array}$ & $\begin{array}{c}\text { Final rank } \\
\text { Of } \\
\text { personnel } \\
\text { criteria } \\
\text { choice }\end{array}$ \\
\hline 0.202 & 0.272 & 0.105 & 0.252 & & & & 0.0191 & 0.083 & 0.032 & 0.075 \\
\hline 0.199 & 0.277 & 0.051 & 0.089 & \multirow{5}{*}{$x$} & & \multirow{5}{*}{$=$} & 0.0184 & 0.084 & 0.016 & 0.026 \\
\hline 0.137 & 0.339 & 0.101 & 0.252 & & 0.943 & & 0.0132 & 0.103 & 0.030 & 0.075 \\
\hline 0.198 & 0.111 & 0.034 & 0.145 & & 0.304 & & 0.0183 & 0.0337 & 0.010 & 0.043 \\
\hline 0.0077 & & 0.059 & 0.051 & & 0.304 & & 0.00073 & & 0.018 & 0.015 \\
\hline 0.055 & & 0.053 & 0.209 & & 0.297 & & 0.0052 & & 0.016 & 0.062 \\
\hline \multirow[t]{4}{*}{0.202} & & 0.151 & & & & & 0.0191 & & 0.046 & \\
\hline & & 0.069 & & & & & & & 0.021 & \\
\hline & & 0.151 & & & & & & & 0.046 & \\
\hline & & 0.224 & & & & & & & 0.068 & \\
\hline
\end{tabular}

Finally in the table 9, the choices \& effective factors on performance appraisal of Melli bank of Mazandaran province with their charters \& ranks have been presented.

Table No.9-ranking of effective factors on performance appraisal choices

\begin{tabular}{|c|c|c|c|c|c|c|c|}
\hline $\begin{array}{l}3 \\
0 \\
0\end{array}$ & choices & 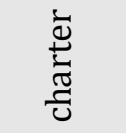 & 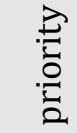 & 3 & choices & 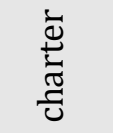 & 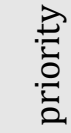 \\
\hline 1 & branch location & 0.0191 & 14 & 15 & budgeting \& resource allotment & 0.010 & 21 \\
\hline 2 & average waiting time & 0.0184 & 15 & 16 & management informational system & 0.018 & 17 \\
\hline
\end{tabular}


A. Sorayaei, S. A. Sajjadi Amiri and S. M. Sajjadi Amiri/ TJMCS Vol .2 No.1 (2011) 195-207

\begin{tabular}{|c|c|c|c|c|c|c|c|}
\hline 3 & credit granting criteria & 0.0132 & 20 & 17 & continual innovation & 0.016 & 18 \\
\hline 4 & behaving manner towards customer & 0.0183 & 16 & 18 & welfare for personnel \& his family & 0.046 & 7 \\
\hline 5 & modern service presentation & $\begin{array}{c}0.0007 \\
3\end{array}$ & 23 & 19 & reward system & 0.021 & 13 \\
\hline 6 & $\begin{array}{c}\text { recognition \& attention to customer } \\
\text { demand }\end{array}$ & 0.0052 & 22 & 20 & salary system & 0.046 & 7 \\
\hline 7 & financial consultation to customers & 0.0191 & 14 & 21 & trust to personnel & 0.068 & 5 \\
\hline 8 & decrease the delayed demanding & 0.083 & 3 & 22 & expertise \& knowledge & 0.075 & 4 \\
\hline 9 & profitability & 0.084 & 2 & 23 & instruction & 0.026 & 12 \\
\hline 10 & rate of asset absorption & 0.103 & 1 & 24 & experience & 0.075 & 4 \\
\hline 11 & decrease the extra expenditure. & 0.0337 & 9 & 25 & work conscience & 0.043 & 8 \\
\hline 12 & the method of appraisal performance & 0.032 & 10 & 26 & organizational commitment & 0.015 & 19 \\
\hline 13 & method of control \& supervision & 0.016 & 18 & 27 & innovation & 0.062 & 6 \\
\hline 14 & $\begin{array}{c}\text { representing goals \& organization } \\
\text { plans }\end{array}$ & 0.030 & 11 & & & & \\
\hline
\end{tabular}

Based on the result of No.9, experience, instruction, expertise \& knowledge are ranked from the first to the third priorities and the choices of budgeting \& resource allotment, recognition \& attention to customer demand \& modern service presentation are ranked from twenty one to twenty three priorities.

\section{3-collection}

First step in performance appraisal of organizations in country is to identify the factors and criteria for starting this system. Determination of the most important factors should be made by regarding to affective factors and criteria .In this study some factors for performance appraisal were identified and ranked that can be helpful for organizations in the decision making for confirmation of modern appraisal system.

Because of the span \& importance of the subject, there have done many studies respecting appraisal of performance \& effective factors upon organizations performance, a number of which were mentioned in the present study.

Regarding the indagation of 4 effective criteria on the performance of Mazandaran Melli Bank branches, respectively: asset \& management, obtained first, personnel became second and customer achieved the third ranks \& among the 27 choices related to these criteria, on the basis of table 9 choices achieved ranks of 1 to 23 .

Regarding the research findings, for the intention of recognition \& ranking of the most effective factors on the performance of the mentioned organization, the following suggestions are presented: planning to gain more assets for branch because of the most importance of this choice. More attention to profitability of branch that is achieved by satisfying the needs of customer and personnel. using the expert personnel in related jobs and ...»more respect \& more trust to personnel for doing their jobs.

\section{4- Suggestions for future studies}

Concerning the presented cases, the following subjects can be represented as future studies resources

- Appraisal \& ranking of effective factors on other organizations performance

- indagation \& comparative study of different organizations appraisal of performance in the country

- distinct indagation of the effect of each of the factors on the performance of the organization. 


\section{5- References}

[1] Alvani, Mehdi, Decision Making \& Determining Government Procedure, Samt Publication, 1379.

[2] Ali, Imran., A Performance Framwork For Small and Medium Enterprise, for the degree of master of sience, Edmonton Alberta, 2003.

[3] Alsyouf Imad., "Methodology and Theory Measuring maintenance performance using a balanced scorecard approach", Journal of Quality in Maintenance Engineering, vol. 12. No.2, 2006.

[4] Asgharpoor, Mohammadjavad, Multi criteria Decision Making, Tehran University Publication, 1383.

[5] Azar, Adel, Gholamrezaei, Davood, ranking the provinces of Iran by using of the DEA method (with human development factors) , seasonal Iran economic researches , 8nd year, no. 27, 1384.

[6] Azar, Adel, Rajabzadeh, Ali, Application Decision Making, Tehran, Negah e Danesh Publication, 1387.

[7] Hosseinabbasi, Laleh, Mosta'an, Mohammad, The Application of New Methods of Performance Appraisal HSE In Oil Industry, Production \& Exploration Magazine, No. 62, 1388.

[8] Chang,D-Y, Applications of the extent analysis method on fuzzy AHP.European journal of operational research,95,649-655, 2001.

[9] Kahraman, c.Ruan, D\& Doj, Fuzzy group decision making for facility location selection, information sciences, 157, 2003.

[10] Mo'meni, Mansoor, New Discussion on Operation Research, Tehran University Publication, 1384.

[11] Saghe' Ei, Ehsan, Performance Appraisal Of Executive Department, The First \& Biggest Expert Site Of Industries Engineers Of Iran, 1387.

[12] Shirchi, hamed, performance appraisal of mazandaran telecommunication by using of EFQM model, MA thesis of Business Administration, 1388. The Guidance Book Of Performance Appraisal Of Executive Department Of Management \& Planning Organization Publication.

[13] Sorayaei, Ali; Pakdin Amiri, Alireza. A Study of Manpower Productivity Status in Mazandaran (North of Iran) Province Payamnor University, The International Conference On Management Sciences and Arts, Gurukul Kangri university, Haridwar, Uttarakhand, India, 2008.

[14] Yazdchi, Mehdi, Performance Management \& Measurement, 9nd Conference of Electricity Distribution Network, Zanjan University, Ordibehesht 1383.

a.sorayaei@gmail.com

alisajjadi86@yahoo.com

s_marzieh_sajjadi@yahoo.com 